Sharif University of Technology
Scientia Iranica
Transactions E: Industrial Engineering
hCIENTIA

\title{
A multi-objective SCOR-based decision alignment for supply chain performance management
}

\author{
M. Rezaei, M. Akbarpour Shirazi*, and B. Karimi \\ Department of Industrial Engineering, Amirkabir University of Technology, 424 Hafez Ave., Tehran, 15875-4413, Iran.
}

Received 10 August 2016; received in revised form 8 April 2017; accepted 17 July 2017

\section{KEYWORDS}

Multi-objective; NSGAII; SCOR model; Decision alignment; Supply chain;

Performance management.

\begin{abstract}
A dynamic integrated solution to three main problems through integrating all metrics using SCOR is proposed in this research. This dynamic solution comprises strategic decisions in high level, operational decisions in low level, and alignment of these two decision levels. In this regard, a human intelligence-based process for high-level decisions and machine-intelligence based Decision Support Systems (DSSs) for low-level decisions are proposed using a novel approach. The presented operational model considers important supply chain features thoroughly, such as different echelons, several suppliers, several manufacturers, and several products, during multiple periods. A multi-objective mathematical programming model is then developed to yield the operational decisions with Pareto efficient performance values and solved using a well-known meta-heuristic algorithm, i.e., NSGAII, the parameters of which are tuned using Taguchi method. Afterwards, an intermediate machine-intelligence module is used to determine the best operational solution based on the strategic idea of the decision maker. The efficiency of the proposed framework is shown through numerical example and then, a sensitivity analysis is conducted for the obtained results so as to show the impact of the strategic scenario planning on the performance of the considered supply chain.
\end{abstract}

(C) 2018 Sharif University of Technology. All rights reserved.

\section{Introduction}

To make agile, responsive, sustainable, robust, effective, and competitive Supply Chain (SC), we need to employ all models and technologies that ensure profitability and stability. In this regard, Supply Chain Management (SCM) decisions are categorized into two levels in this research, i.e., human-intelligence and machine-intelligence based decisions, based upon their nature. We develop a process-based method for high-

\footnotetext{
*. Corresponding author. Tel.:+98 2164545370 ; Fax: +982166954569

E-mail address: akbarpour@aut.ac.ir (M. Akbarpour Shirazi)
}

doi: $10.24200 /$ sci. 2017.4463 level decisions, a multi-objective method for low-level decisions, and an intermediate multi-objective method for aligning high- and low-level decisions using a novel approach.

Due to SCM resource constraints, only a limited number of objectives are able to take high priorities [1]. We employ a prioritization method to deal with the multi-objective problem in the strategic level. This paper aims at two main objectives: (1) improving the Supply Chain Performance Management (SCPM) by aligning different decision levels in the integrated process of transforming strategies into operational programs; and (2) improving the SCPM by using appropriate decision-making models in each level.

Performance management is a necessity for organizational competitiveness [2]. It determines what must be maintained as the strong point and what 
needs to be overcome as the weak point [3]. The important aspect that has impacts on the success and efficiency of optimization models is to design such models based on reliable performance indicators. Supply Chain Operations Reference (SCOR) model is one of the important models in performance management that contains major processes, metrics, and standard characteristics [4]. The SCOR model divides major metrics into many partial indicators at lower levels.

Although the main goals of SCPM are pursued at the strategic level, the activities that directly create value-added products and services are involved in the operational level [5]. Therefore, the alignment of decisions is an important matter that should be investigated [6]. However, most of the researches in the literature consider that the decisions at different levels of SC are independent. As an attempt to fill the mentioned gaps, an SCOR based framework for measuring, evaluating, and improving SCPM is proposed in this research.

The remainder of this paper is organized as follows. Section 2 presents a summary of recent and major studies carried out on SCPM. In Section 3, the main new framework of SCPM is described. Solution approach is presented in Section 4. Section 5 comprises problem description, in which a sample $\mathrm{SC}$ is illustrated. Techniques and tools used in this research are explained in Section 6. Experimental design is explained in Section 7 . Section 8 discusses computational results, in which illustrative tables and figures are presented. Finally, Section 9 provides the conclusions by discussing the advantages of the proposed framework and further research areas as well.

\section{Literature survey}

\subsection{Review papers}

Because of the importance of SCPM, significant studies have been conducted on this topic and many models have been developed so far. In this regard, Estampe et al. (2013) classified and discussed the most important frameworks for performance management in a review paper [7]. They defined five levels for SC maturity grid at first and then compared 16 frameworks including type of usage, conditions and constraints, degree of conceptualization, and established indicators. They also presented the applications and limitations of the selected frameworks. Singh and Acharya (2014) investigated the effective factors on the performance of SC [8]. Schaltegger et al. (2014) carried out a structured review of the existing literature and researches in the field of sustainable SC's measurement and improvement [9]. A systematic literature review of SCOR model applications with special attention to environmental issues was carried out by Ntabe et al. (2015) [10].

\subsection{Concepts}

Performance measurement provides important measures and tools for assessing the outputs and makes the overall improvement in SC [9]. One of the key elements in an efficient and profitable SCM is to employ an effective performance measurement system [11]. Kocaoğlu et al. (2013) emphasized the structural integration of performance measurement and quantification of models for selecting SC strategies [12].

SCPM is an important issue in the competitive business environments and plays a vital role in defining the objectives, evaluating the results, and determining the future measures. Because of the importance of SCPM, significant studies have been conducted on this topic and many models have been developed so far. In this regard, Estampe et al. classified and discussed the most important frameworks for performance management in a review paper [7].

Flexibility, output, and resources are the three important aspects of SC performance [13]. However, Gunasekaran et al. classified the performance metrics into strategic, tactical, and operational levels [14]. Some researches presented administrative frameworks and step-by-step methods for performance improvement. Cai et al. introduced a framework for performance management and proposed a new approach for selecting key performance metrics (KPIs) in strategic level [15]. Elgazzar et al. suggested a performance assessment framework based on a financial approach using SCOR model and Analytic Hierarchy Process (AHP) [16]. Agami et al. proposed a performance improvement model to determine the bottleneck of KPIs using a successive five-step process [11].

\subsection{Mathematical models}

A given $\mathrm{SC}$ has a multi-level, multi-criteria, and interrelated structure in which the performance improvement of one unit does not clearly assure the optimized performance of the whole SC [17]. Agami et al. developed a fuzzy model so as to identify the critical KPIs [18]. In this regard, Blanco presented an Integer Linear Programming (ILP) model including three objectives and extended a solution approach for solving the studied problem [19]. Liu and Papageorgiou presented a multi-objective Mixed Integer Linear Programming (MILP) model to optimize a multiperiod problem dealing with production, distribution, and capacity planning in an SC in process industries [20]. Hamta et al. developed a hybrid Particle Swarm Optimization (PSO) algorithm for a multi-objective assembly line balancing problem with flexible operation times, Sequence-Dependent Setup Times (SDST), and learning effect [21]. Kolahan and Kayvanfar developed a heuristic algorithm approach for scheduling of multicriteria unrelated parallel machines [22].

Celik et al. developed a solution method using 
the Genetic Algorithm (GA) to solve a multi-period real-time model [23]. High usability and exciting philosophy of Goal Programing (GP) for practitioners and researchers in handling decision-making problems with multi-objective structures made it very applicable [24,25]. In [26], an interactive GP model was created for virtual manufacturing cells procedure, while Mahdavi et al. (2011) developed a fuzzy GP method for solving a multi-objective model of production planning in a virtual manufacturing system [27].

Wong developed a Decision Support System (DSS) using fuzzy logic based on expert judgments to select 3PL [28]. Xu et al. proposed a multiobjective model to optimize a multi-period SC with stochastic demand using a fuzzy method [29]. Cai et al. developed a multi-objective optimization model based on SCOR indicators and solved the problem using PSO algorithm [30].

\section{4. $S C O R$}

Designing the models based on reliable performance indicators is one of the most important aspects affecting the success and efficiency of optimization models. SCOR model is the performance assessment framework in the literature that provides the mentioned comprehensiveness and reliability to respond to our concerns. Zhang and Reimann used five high-level indicators of SCOR, simultaneously, to optimize SC performance and proposed a five-objective multi-period mathematical model for planning a two-echelon SC with deterministic demand by applying customized indicators [31]. Kocaoğlu et al. presented a multiobjective model to align the operational decisions with the strategic decisions using SCOR framework [12]. They determined the relative importance of different strategies using AHP and the hierarchical structure of SCOR and then selected the best scenarios in which SC performance was optimal by applying Technique for Order of Preference by Similarity to Ideal Solution (TOPSIS) method.

\subsection{Research gap}

Despite devoting many efforts over the past decade, there are still gaps in this area and, owing to some shortcomings, the capabilities of SCPM frameworks are not adequate [12,32]. Obviously, one element is not able to optimize the whole SC. The question is how we must manage such complex system to be able to achieve continuous and acceptable productivity [33]. Attaining appropriate optimization approach and continuous improvement as well as proper guarantee of them through the $\mathrm{SC}$ is the critical issue that should be addressed in different levels of SC studies [34]. Management strategies should be designed based on the changing conditions of the market [35]. In many studies, different parts of the $\mathrm{SC}$ are assumed independent and their internal relations and changing behaviors are not considered. In addition, there are some defects in analysis of feedback in design and implementation stages in order to adapt the behavior of SC for the environmental changes [36]. Many of the studies are not comprehensive enough and cannot evaluate and improve the performance based on the performance indicators. Static nature of some proposed systems for performance evaluation is one of the critical issues. The proposed quantitative models mostly focus on individual factors such as fiscal measures to assess SC performance [37]. The problem is how we can model and analyze the strategic and operational objectives, and connect them to each other appropriately [12]. According to Wang et al. [38], despite the ability of SCOR to provide appropriate indicators, it has not been used enough in the literature. According to the recommendations in the literature, it is better to employ comprehensive and reliable indicators such as SCOR to develop the mathematical models for performance management [39].

In conclusion, with respect to the importance of SCPM and mentioned deficiencies, more studies have to be carried out to cover these research gaps. Finally, the main problems and defects are presented according to the literature. It can be claimed that most of the current studies suffer from one or more of the following shortcomings:

- Limited number of studies on the combination of related concepts (keywords of this paper) and taking advantage of their synergies;

- Inability to support the continuous improvement;

- Local optimization;

- Lack of comprehensive and acceptable performance evaluation models.

As an attempt to fill the mentioned gaps, an SCOR based framework for measuring, evaluating, and improving SCPM is proposed in this research. The presented framework is comprehensive, dynamic, and continuous. It applies sciences, techniques, and tools, namely, SCPM, strategic planning, multi-objective optimization, and SCOR model, to a new SCPM.

\section{A SCOR-based dynamic SCPM framework}

To design an integrated SCPM structure, SCOR model has been used. The SCOR model divides major metrics into many partial indicators at lower levels. Given the hierarchical structure of SCOR, achieving higher values for performance indicators at any level enables better performance through the entire SC. This detailed structure enables us to design acceptable and comprehensive multi-objective functions. Figure 1 shows the new SCPM proposed in this study. 


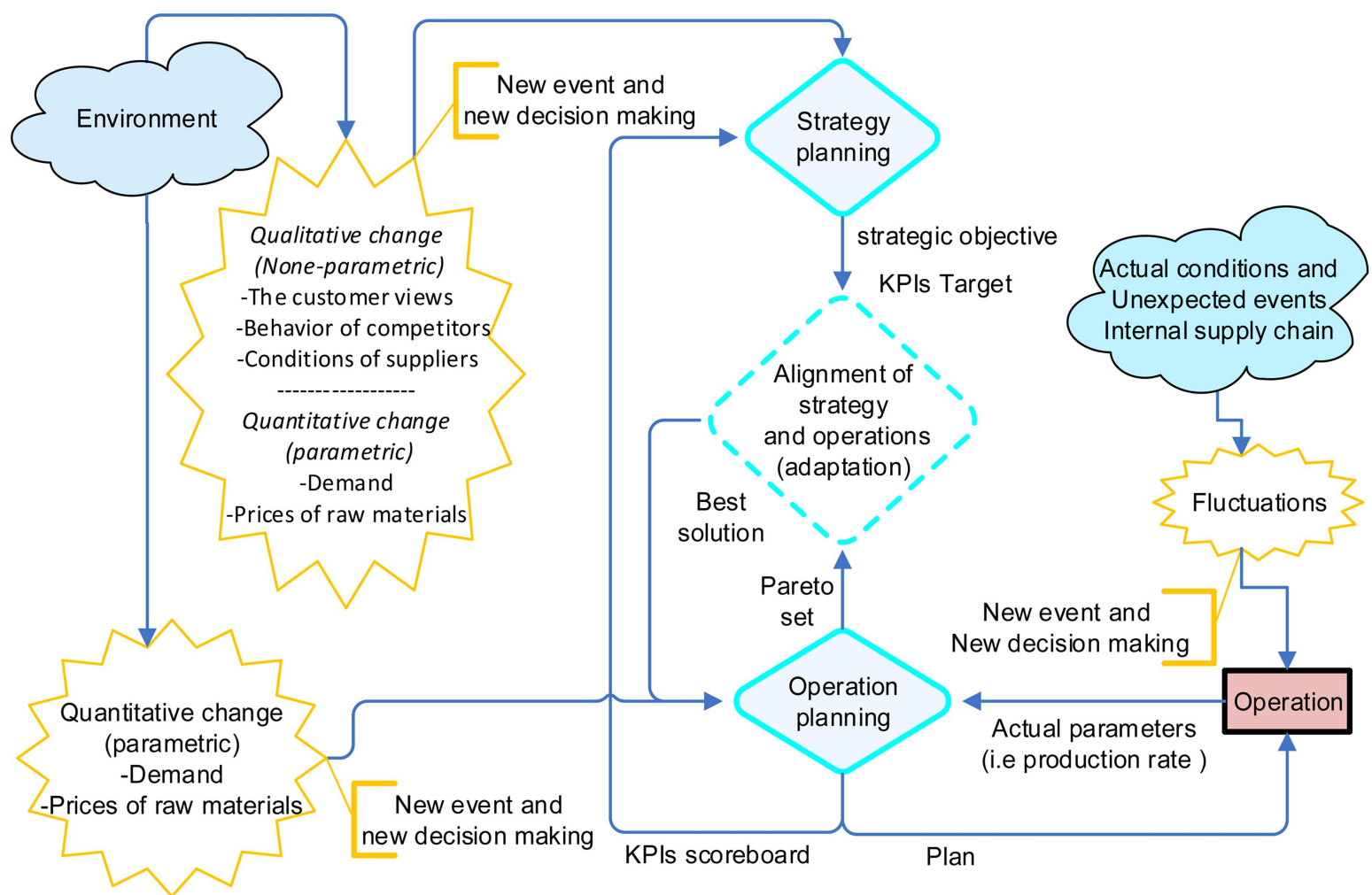

Figure 1. The logical design for integrated SCOR-based SCPM framework.

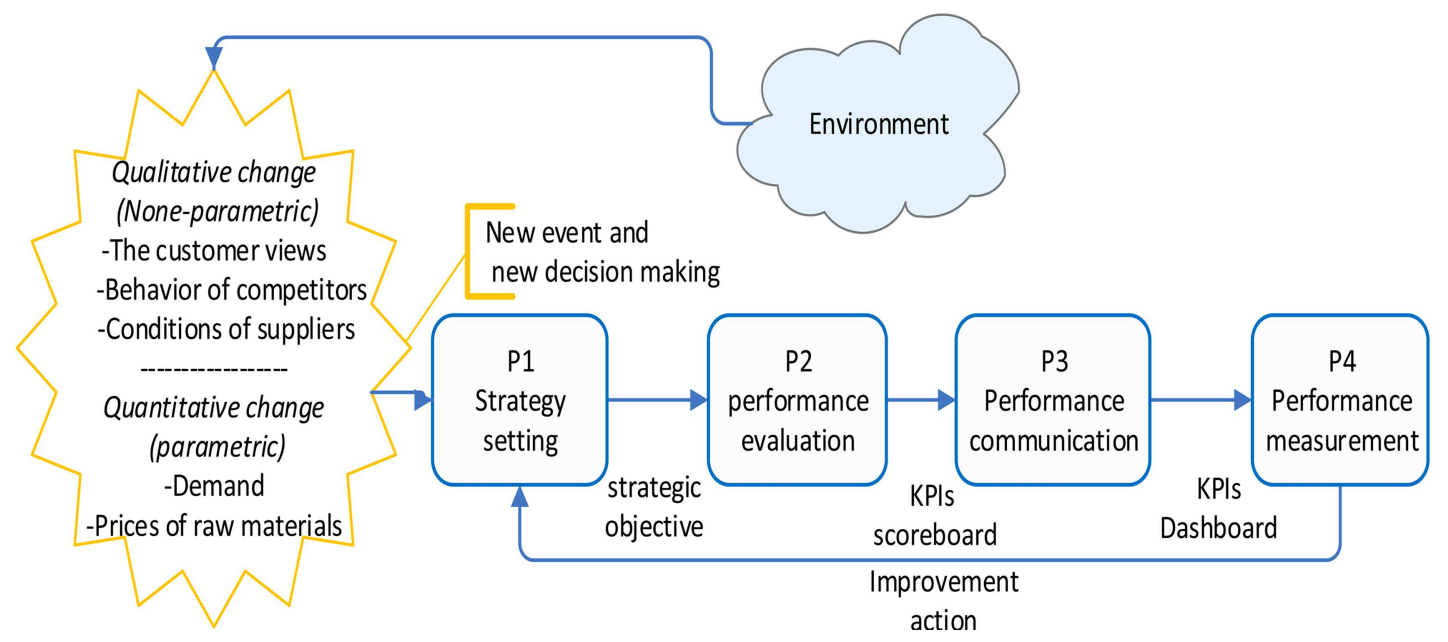

Figure 2. The human-intelligence based decision-making.

Given such adaptive approach, we assume that all internal and external changes affecting decisions are detected and proper responses for these events are then presented. Therefore, for adaptation to the latest changes, related decisions will be updated. In other words, event-driven policy is used. Based on the nature of events and type of decisions, the new definition proposed in this paper categorizes decisions into two groups. The first category is human-intelligence based decisions. Such decisions are taken at the highest level of SCPM and influence all the lower levels. The second group of decisions is machine-intelligence based deci- sions. These decisions are less complex than humanintelligence ones and more structured. Typically, problems such as inventory control, and production and distribution planning are considered at this level.

A process model is usually used for decisions on strategy planning in the literature, which only matches the capabilities of human intelligence [11]. In this paper, a specific process is developed for humanintelligence based decisions. The main phases of the proposed process of human-intelligence based decisionmaking are illustrated in Figure 2.

The first phase (P1) defines the strategic objec- 
tives. In this step, we employ a prioritization method to deal with the multi-objective problem. In the second phase (P2), the current performance of each metric is evaluated and the gap between actual and target values is measured (according to Table 1). In the third phase (P3), the results of operations and analysis of metrics are demonstrated in a dashboard to determine which performance metric does not meet predetermined expectations. Such metrics are identified as performance bottlenecks. The performance results which are the "operational level's output" have impact on strategic design of the next level. In the final phase (P4), according to the results, management takes appropriate measures to improve and achieve higher levels of performance metrics in subsequent operations.

Table 1 employs the first level of SCOR's metrics and shows the analysis of the current condition, the strategy setting, priority of performance objectives, and the gap between current condition and target value. First, numerical column shows the current condition of the SCPM. The next three columns show the benchmark values of each metric in three levels, i.e., parity, advantage, and superior [40]. Grey cells indicate the priority of each of the five objectives. Finally, the last column shows the gap between current condition and target value. Once Table 1 is set, a new strategic plan can be designed. By determining the SC objective priorities, all plans and programs are designed using these priorities while we try to fill the gap. This is the main approach to align all SCPM decisions.

To deal with operational planning problems, we can develop DSSs using machine-intelligence. All quantitative models including Linear Programing (LP), Non-Linear Programing (NLP), fuzzy, meta-heuristic, simulation, deterministic, stochastic, or a combination of them can be used at machine-intelligence level.

Once any change or update comes up on decisionmaking modules in the strategic and operational levels, an intermediate decision-making module is updated to align high- and low-level decisions (Figure 3). In this case, the module selects a solution from the Pareto optimal solutions provided by the mathematical model at the low level which has the highest alignment with the strategic objectives of SCM. This module has

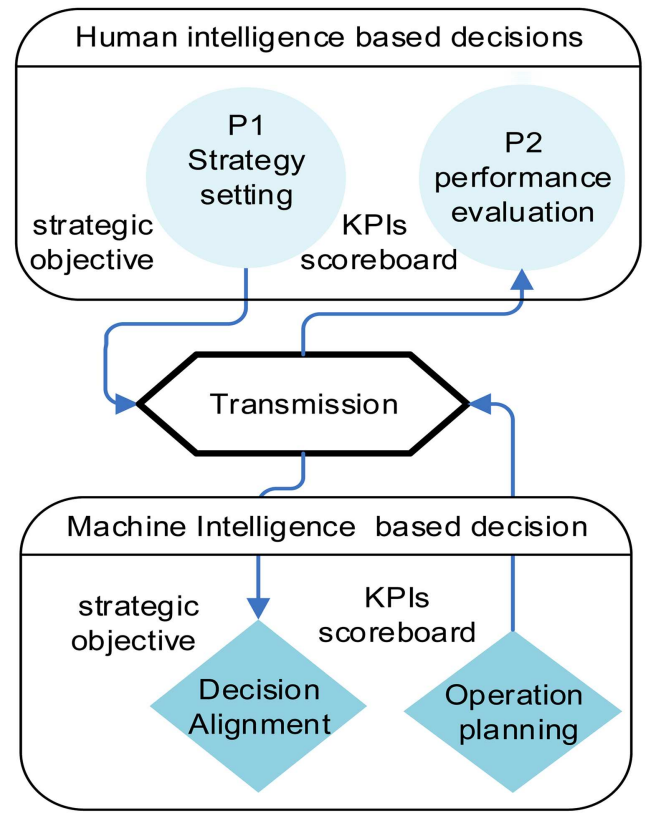

Figure 3. The relationship between human- and machine-intelligence based decisions.

been developed on the basis of machine intelligence. In this case, the multi-objective function of operational plan should be adjusted according to strategic goals and priorities. Fuzzy and TOPSIS approaches could be employed so as to develop this module as well.

\section{Solution approach}

Any change in parameters will be detected as a new event and, therefore, will cause change in inputs of the decision model. Consequently, the optimization model is run again in the correspondent level and the best decision will be updated. Then, the decisions in all levels will be aligned with each other using the appropriate decision models.

\subsection{Levels of decision}

Strategy setting: First, the SC's priorities are determined. For some objectives, worse values than the corresponding single-objective optimum values might be considered. In such a condition, accessibility to solutions with higher values for higher priority objectives

Table 1. Determining the strategy and objectives of SCOR [40].

\begin{tabular}{|l|l|l|l|l|l|l|}
\hline \multirow{2}{*}{ Attribute } & \multirow{2}{*}{ Metric (level 1) } & \multirow{2}{*}{ You } & \multicolumn{2}{l|}{ Benchmark } & \multirow{2}{*}{ Gap } \\
\cline { 5 - 6 } & & & Parity & Advantage & Superior & \\
\hline Reliability & Perfect order fulfilment & $95 \%$ & $92 \%$ & $95 \%$ & $98 \%$ & $3 \%$ \\
\hline Responsiveness & Order fulfilment cycle time & 14 days & 8 days & 6 days & 4 days & 8 days \\
\hline Flexibility & Supply chain flexibility & 62 days & 80 days & 60 days & 40 days & 0 days \\
\hline Cost & Supply chain management Cost & $12.2 \%$ & $10.8 \%$ & $10.4 \%$ & $10.2 \%$ & $1.4 \%$ \\
\hline Assets & Cash-to-cash cycle time & 35 days & 45 days & 33 days & 20 days & 2 days \\
\hline
\end{tabular}


increases. In another situation, similar to what is explained in Table 1, one can consider the least acceptable values for "Advantage" and "Parity" objectives and optimize one of the objectives as "superior" at the most possible value. Each of these approaches is a different strategic scenario, which could be taken in high level of SC and applied to the lower levels. The multiobjective mathematical model is initially separated into the single-objective problems. In other words, in order to obtain the best possible value for each objective, one should optimize each objective separately. By doing so and setting the SC's priorities as described above, the ideal solutions are obtained, which will then be used by TOPSIS method (Machine decisions or operational decisions).

Operational decisions: On the other hand, in the second step, the multi-objective problem is solved in parallel with NSGAII algorithm to achieve the feasible solutions to the entire problem regarding all constraints. These solutions are not optimum with respect to the obtained optimum values from the first step. The solutions gained at this step are sorted based on non-domination method and the best Pareto solutions could be chosen by the decision maker (Operational decisions).

Decisions alignment: Finally, in the third step, we need to align the strategic decisions with the operational ones. To do so, the Pareto set solutions are used in TOPSIS method, as a multi-criteria decision analysis, to yield the best compromise solutions which satisfy the different objectives to the possible extent. Actually, TOPSIS compares the gained feasible solutions of Pareto set with the ideal solutions. In other words, TOPSIS stands on the concept that the selected alternative should have the shortest geometric distance from the positive ideal solution while there should be the longest geometric distance from the negative ideal one.

\section{Problem formulation}

In order to demonstrate how the new proposed framework performs, a sample SC is suggested and a numerical example is then solved and described to show the efficiency of the proposed approach. Suppose a two-echelon SC including several suppliers and manufacturer. Several products of a family are produced in this $\mathrm{SC}$ and planning is accomplished during multiple periods. A multi-objective multi-period two-echelon mathematical model for the considered SC is proposed in this section. The other assumptions are summarized as follows:

- The parameters in each period are assumed to be known, deterministic, and fixed throughout the planning periods;

- The objective of the proposed model is to minimize the total cost of logistics and maximize the agility and reliability in the considered SC, simultaneously;

- In each period, demands are given and determined;

- Both fixed and variable transportation costs from suppliers to manufacturers are considered.

\subsection{The mathematical model}

\section{Notations}

Indices

I Number of suppliers;

$J \quad$ Number of plants;

$L \quad$ Number of products;

$N \quad$ Number of materials;

$T \quad$ Number of periods;

Parameters

$D_{l j t} \quad$ The demand of product $l$ from plant $j$ in period $t$;

$U r_{n l} \quad$ The amount of material $n$ to produce one unit of product $l$;

Caps $_{\text {nit }} \quad$ Capacity of supplier $i$ to supply material $n$ in period $t$;

Capp $_{l j t} \quad$ Capacity of plant $j$ to produce product $l$ in period $t$;

$V m r_{j} \quad$ The volume of raw materials at plant warehouse;

$V m p_{j} \quad$ The volume of the finished product at plant warehouse;

$P c_{l j} \quad$ Production cost of one unit of product $l$ (with the exception of raw material) by plant $j$;

$\mathrm{Pr}_{n i} \quad$ Price of material $n$ determined by supplier $i$;

$H m r_{n j} \quad$ Inventory holding cost of material $n$ at plant $j$;

$H m p_{l j} \quad$ Inventory holding cost of product $l$ at plant $j$;

$Q p_{l} \quad$ Required space per unit of product $l$;

$Q r_{n} \quad$ Required space per unit of material $n$;

$F_{c r} \quad$ Fixed transportation cost for handling material $l$ from supplier $i$ to plant $j$;

$V c r_{n i j} \quad$ Transportation cost for handling a unit of material $l$ from supplier $i$ to plant $j$;

$T d r_{n i j t} \quad$ Delivery time of a unit batch of material $n$ from supplier $i$ to plant $j$ in period $t$;

$\operatorname{Trmax}_{n i j t}$ Due date for delivering a unit batches of material $n$ from supplier $i$ to plant $j$ in period $t$; 


$$
\begin{aligned}
& B s m_{n i} \quad \text { Batch size of material } n \text { at supplier } i \text {; } \\
& S S m_{n j t} \quad \text { Safety stock of material } n \text { at plant } \\
& \text { warehouse } j \text { in period } t \text {; } \\
& \mathrm{Cbl}_{l j} \quad \text { Backlog unit cost of product } l \text { in plant } \\
& j \text { in period } t \text {; }
\end{aligned}
$$

\section{Decision variables}

$X_{n i j t} \quad$ Amount of supplied material $n$ by supplier $i$ to plant $j$ in period $t$;

$Y_{l j t} \quad$ Amount of produced product $l$ by plant $j$ in period $t$;

$I R m_{n j t} \quad$ Inventory level of material $n$ at plant $j$ at the end of period $t$;

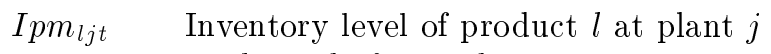
at the end of period $t$;

$T R_{n i j t} \quad$ Receiving time of material $n$ from supplier $i$ by plant $j$ in period $t$;

$W_{\text {nijt }} \quad 1$, if plant $j$ orders material $l$ from supplier $i$ in period $t ; 0$, otherwise;

$B L g_{l j t} \quad$ Backlog level of product $l$ at plant $j$ in period $t$;

$Q_{l j t} \quad$ Sale amount of product $l$ at plant $j$ in period $t$;

Objective functions

$T C \quad$ The cost of supply chain;

$T C_{s}($ Cost $) \quad$ The costs of the suppliers;

$T C_{p}($ Cost $) \quad$ The costs of the plants;

Ag(Agility) Flexibility: Surplus capacity;

Ags(Agility) Flexibility: Surplus capacity of suppliers;

Agp (Agility) Flexibility: Surplus capacity of plants;

Rel(Reliability)Perfect order fulfilment;

\section{Mathematical model}

Minimize TC (Cost)

$$
\begin{aligned}
T C= & T C_{s}+T C_{p}, \\
T C_{s}= & \sum_{t} \sum_{n} \sum_{i} \sum_{j} X_{n i j t} . P r_{n i} \\
& +\sum_{t} \sum_{n} \sum_{i} \sum_{j} W_{n i j t} . F c r_{n i j} \\
& +\sum_{t} \sum_{n} \sum_{i} \sum_{j} X_{n i j t} . V c r_{n i j} \\
& +\sum_{t} \sum_{n} \sum_{j} H m r_{n j} . I R m_{n j t}
\end{aligned}
$$

$$
\begin{aligned}
T C_{p}= & \sum_{t} \sum_{l} \sum_{j} Y_{l j t} . P c_{l j} \\
& +\sum_{t} \sum_{l} \sum_{j} H m p_{l j} . I m p_{l j t} \\
& +\sum_{t} \sum_{l} \sum_{j} C b l_{l j} . B L g_{l j t} .
\end{aligned}
$$

Maximize $A g$ (Agility)

$$
\begin{aligned}
& A g=A g s+A g p \\
& A g s=\sum_{t} \sum_{n} \sum_{i}\left(C a p_{n i t}-\sum_{j} X_{n i j t}\right), \\
& A g p=\sum_{t} \sum_{l} \sum_{j} C a p_{l j t}-Y_{l j t} .
\end{aligned}
$$

Maximize Rel(Reliability)

$$
\begin{aligned}
& \operatorname{Re} l=\sum_{t} \sum_{l} \sum_{j} \operatorname{Re}_{t l j}, \\
& \operatorname{Re} l_{t l j} \leq Y_{l j t}+I p m_{l j t} \quad \forall_{l, j} \text { and } \forall_{t} \in[1, T], \\
& \operatorname{Re} l_{t l j} \leq D_{l j t} \quad \forall_{l, j} \text { and } \forall_{t} \in[1, T] .
\end{aligned}
$$

The first main objective minimizes total costs of system, including costs of suppliers and manufacturers (Eq. (1)). Supply costs (Eq. (2)) comprise raw material costs, fixed transportation costs of raw materials and variable transportation costs of materials to facilities, and holding cost of raw materials at plants in each period. Eq. (3) signifies production costs including manufacturing costs, holding costs of finished products at plants, and backlogged costs in each period. The second main objective maximizes the system agility (Eqs. (4)-(6)). The most significant metric to measure agility of an SC is flexibility, which reflects the ability of reacting to external influences. According to Sabri and Beamon (2000) [41], flexibility could be measured through surplus capacity. In this paper, in order to evaluate flexibility, the maximum extra demand, which could be satisfied through surplus capacity of the SC, is considered. The third main objective maximizes reliability of the system. Reliability could be defined as ability of satisfying customer demands on time with the right quantity. Perfect order fulfillment could be called the first-level metric of reliability (Eq. (7)). The perfect order fulfillment depends on the minimum of products available (Eq. (8)) and demands (Eq. (9)) in the same period. The applied constraints of the considered SC are as follows: 


\section{Subject to:}

\section{Inventory level}

Note: Inventory in the initial time period (period 0) is zero:

$$
\begin{aligned}
& I R m_{n j t}=I R m_{n j, t-1}+\sum_{i} X_{n i j t}-\sum_{l} U r_{n l} . Y_{l j t}, \\
& \forall_{t, n, j}, \\
& I P m_{l j t}=I P m_{l j, t-1}+Y_{l j t}-Q_{l j t}, \quad \forall_{t, l, j}, \\
& I R m_{n j t} \geq S S m_{n j t}, \quad \forall_{t, n, j},
\end{aligned}
$$

Volume warehouse

$$
\begin{aligned}
& \sum_{n} Q r_{n} . I R m_{n j t} \leq V m r_{j}, \quad \forall_{t, j}, \\
& \sum_{l} Q p_{l} . I p m_{l j t} \leq V m p_{j}, \quad \forall_{t, j} .
\end{aligned}
$$

\section{Product capacity}

$$
\begin{aligned}
& \sum_{j} X_{n i j t} \leq \operatorname{Cap}_{n i t}, \quad \forall_{n, i, j, t}, \\
& Y_{l j t} \leq \operatorname{Cap}_{l j t}, \quad \forall_{l, j, t} .
\end{aligned}
$$

\section{Delivery time}

$$
T d r_{n i j t} \times\left(X_{n i j t} / B s m_{n i}\right) \leq T r \max _{n i j t}, \quad \forall_{n, i, j, t}
$$

where:

$$
T d r_{n i j t} . X_{n i j t} / B s m_{n i}=T R_{n i j t}, \quad \forall_{t, l, j} .
$$

\section{Backlog demand}

$$
\begin{aligned}
& B L g_{l j t}=B L g_{l j, t-1}+D_{l j t}-Q_{l j t}, \quad \forall_{t, l, j}, \\
& B L g_{l j t} \leq \alpha_{l j t} . D_{l j t}, \quad \forall_{t, l, j}, \\
& D_{l j t}-Q_{l j t} \leq B L g_{l j t}, \quad \forall_{t, l, j} .
\end{aligned}
$$

\section{Logical}

$$
\begin{aligned}
& W_{n i j t} . M_{1} \geq X_{n i j}, \quad M_{1 ; \text { A very big number }}, \\
& W_{n i j t} \in\{1,0\}, \quad \forall_{n, i, j}, \\
& X_{n i j t}, Y_{l j t}, I R m_{n j t}, I p m_{l j t}, T R_{n i j t}, W_{n i j t}, \\
& \quad B L g_{l t}, Q_{l j t} \geq 0, \quad \forall_{n, l, i, j} .
\end{aligned}
$$

Constraint sets (10) and (11) define the inventory balancing equations for raw materials and finished products at the warehouses of the manufacturer, respectively. Constraint (12) demonstrates the balance of raw material safety stock at the warehouse of the manufacturer. Constraints (13) and (14) specify the limited storage spaces of raw materials and finished products at the warehouses of the manufacturer, respectively. The row material capacity of each supplier for each material in each period is ensured through Constraint (15). The production capacity of each manufacturer for each product in each period is ensured through Constraint (16). Constraints (17) and (18) deal with on time delivery and guarantee the limited delivery time for the manufacturers. Constraint (17) shows that the delivery time of raw materials by suppliers is less than the maximum acceptable time determined by manufacturers. Constraint (18) demonstrates delivery time of raw materials from suppliers to manufacturers in each period. Constraints (19)-(21) are concerned with the amount of backordered demand. In this context, Eq. (19) shows the balance of backordered numbers of products in any two consecutive periods. Constraints (20) and (21) demonstrate the boundary of backordered amounts of each product with respect to its demand for the manufacturers. Constraint (22) ensures that the supplied raw material $n$ will be delivered to manufacturer $j$ from supplier $i$ if and only if the corresponding supplier is established. Finally, Constraints (23) and (24) show the binary variables and non-negativity constraint, respectively.

\section{Technique and tools}

\subsection{Non-dominated sorting genetic Algorithm II}

Optimization of conflicting objectives could be investigated in terms of multi-objective optimization. Evolutionary Algorithms (EAs) are potent stochastic search methods which mimic the Darwinian principles of natural selection and are adequate to solve optimization problems with large search space (Anagnostopoulos and Mamanis, 2010). Up to now, numerous Multi-Objective Evolutionary Algorithms (MOEAs) have been suggested in the literature. Non-dominated Sorting Genetic Algorithm II (Deb et al., 2002) [42] is one of the most commonly used multi-objective algorithms among researchers. In this research, an effort is made to apply NSGAII to the considered multiechelon SC problem.

\subsection{Solution representation}

It is obvious that all demand values are integer and positive. In order to represent different points of solution space, a general structure with capability of showing different variables is used. This matrix-based structure has a dimension of $2 \times \alpha$. Since decision variables of the considered problem are more than one, there are differ- 
ent matrices with different values of $\alpha$. For example, $X_{n i j t}$ is four-dimensional variable and $\alpha$ represents $N \times$ $I \times J \times T$. The contents of the first and second columns indicate "the value of this variable in that point" and "variable index," respectively. As an instance, '27' denotes that the number of 27 units of material $n$ are supplied by supplier $i$ to manufacturer $j$ in period $t$. A similar structure with different dimension is employed for the rest of variables, such as $I R m_{n j t}$, so as to represent the chromosome (variable). It is obvious that $\alpha$ is different for the matrix that shows other variables. Figure 4 shows the structure of solution representation. By using the above-mentioned structure, a random initial population is generated. These generated solutions should be firstly sorted based on non-domination, which is explained in the next subsection.

\subsection{Non-dominated sorting algorithm}

To sort a population according to the level of nondomination, each solution should be compared with every other solution in the population to recognize whether it is dominated or not. In fact, the idea behind non-dominated sorting procedure is using a ranking selection method to highlight good points and a niche method should be employed so as to retain steady subpopulations of good solutions. Owing to determining solutions of the first non-dominated front, in a naive approach, each solution could be compared with others in the population to realize whether it is dominated or not. Consequently, all individuals located in the first non-dominated front are found in this step. In order to determine the individuals in the second and higher non-dominated levels, the solutions of the first front are discounted temporarily and the above procedure is repeated (Deb et al., 2002) [42].

\subsection{Diversity mechanism}

Accompanied by convergence on the Pareto-optimal set, finding good solutions spread in the obtained set of solutions by an EA is preferred. To acquire an approximation of solutions' density surrounding a specific individual in the population, the average distance of two points on either side of this point along each of the objectives should be computed. The quantity $i_{\text {distance, }}$ named "crowding distance," is an estimate of the size of the largest cuboid comprising the point $i$ without any other point in the population. In point of fact, the value of total crowding distance is computed as the sum of individual distance values corresponding to each objective. A solution positioned in a less dense cuboid is permitted to have a higher probability to survive in the next generation. The crowded-comparison operation (Figure 5$)$ or $(\prec n)$ must be employed, after allocating a crowding distance to all individuals with the intention of comparing two individuals for their extent of nearness to other ones, which directs the selection procedure at the various stages of the algorithm toward a uniformly spread-out Pareto-optimal front (Deb et al., 2002) [42].

\subsection{Selection mechanism}

Parent population, named $P_{0}$, should be firstly ran-

\begin{tabular}{|c|c|c|c|c|c|c|}
\hline & $\ldots$ & 27 & $\ldots$ & & \multirow[b]{2}{*}{$2^{*} \alpha$} & \multirow[b]{2}{*}{$\alpha=N \times I \times J \times T$} \\
\hline$X_{1111}$ & $\ldots$ & $X_{\text {nitt }}$ & $\ldots$ & $X_{\text {NIJT }}$ & & \\
\hline & $\cdots$ & & $\cdots$ & & \multirow[b]{2}{*}{$2^{*} \alpha$} & \multirow[b]{2}{*}{$\alpha=L \times J \times T$} \\
\hline$Y_{111}$ & $\ldots$ & $Y_{l i}$ & $\ldots$ & $Y_{\mathrm{LTT}}$ & & \\
\hline & $\ldots$ & & $\ldots$ & & \multirow[b]{2}{*}{$2^{*} \alpha$} & \multirow{2}{*}{$\alpha=N \times J \times T$} \\
\hline$I R m_{111}$ & $\ldots$ & $I R m_{n i}$ & $\ldots$ & $I R m_{\mathrm{NJT}}$ & & \\
\hline & $\ldots$ & & $\cdots$ & & \multirow[b]{2}{*}{$2^{*} \alpha$} & \multirow{2}{*}{$\alpha=L \times J \times T$} \\
\hline $1 p m_{111}$ & $\cdots$ & $I_{p m_{l i t}}$ & $\ldots$ & $I p m_{\mathrm{LJT}}$ & & \\
\hline$T R_{l 111}$ & $\ldots$ & $T R_{\text {niit }}$ & $\begin{array}{l}\cdots \\
\cdots\end{array}$ & $T R_{\text {NIJT }}$ & $2^{*} \alpha$ & $\alpha=N \times I \times J \times T$ \\
\hline & $\cdots$ & & & & \multirow[b]{2}{*}{$2^{*} \alpha$} & \multirow[b]{2}{*}{$\alpha=N \times I \times J \times R$} \\
\hline$W_{1}$ & $\ldots$ & $W_{1}$ & 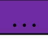 & $W_{\text {NIJT }}$ & & \\
\hline & $\ldots$ & & $\ldots$ & & \multirow[b]{2}{*}{$2^{*} \alpha$} & \multirow[b]{2}{*}{$\alpha=L \times I \times T$} \\
\hline$B L g_{111}$ & $\ldots$ & $B L g_{l i t}$ & $\ldots$ & $B L g_{\mathrm{LJT}}$ & & \\
\hline & $\ldots$ & & $\ldots$ & & \multirow[b]{2}{*}{$2^{*} \alpha$} & \multirow[b]{2}{*}{$\alpha=L \times J \times T$} \\
\hline$Q_{111}$ & $\ldots$ & $Q_{l i t}$ & $\ldots$ & $Q_{\mathrm{LTT}}$ & & \\
\hline
\end{tabular}

Figure 4. Representation of the structure of chromosomes in the considered problem.

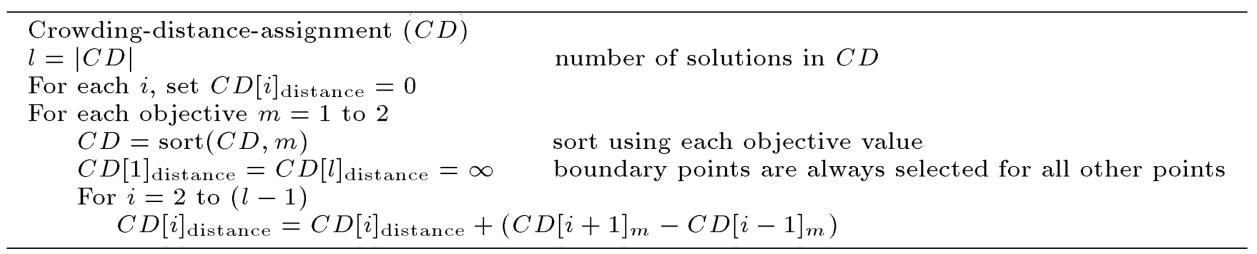

Figure 5. Pseudo-code of crowding distance procedure in non-dominated set. 
domly generated, which is sorted based on the nondomination. Each individual is then assigned a fitness or rank equal to its non-domination level. Selection operator chooses a set $P^{\prime} \subseteq P_{0}$ of the chromosomes (better members of the population with better fitness values), which will be given the chance of mating and mutating. The common binary tournament selection operator based on the crowded-comparison operator $\prec_{n}$ is employed in this research so as to encode NSGAII.

\subsubsection{Crossover and mutation operators}

Generating offspring by taking two parent chromosomes from the mating pool is called crossover. This process is carried out with the intention of finding better solutions. The crossover operator is applied according to a probability $p_{c}$ over the opted offspring attained through roulette wheel method. Among several common crossover operators, a standard twopoint crossover is applied in this study with the purpose of generating two offspring from two parent solutions. Having randomly selected two points in a string, the sub-strings between the crossover points are interchanged. Figure 6 depicts applying the crossover operator to the two selected parents.

Mutation operator is commonly utilized with the purpose of diversifying the population to avoid premature convergence on multiple copies of one individual. Once the offspring is attained, a mutation operator with a probability $p_{m}$ could be employed. Among various types of mutation operators, the swap mutation had the best performance in the problem at hand. This operator swaps two genes in the selected chromosomes; also, it keeps away from getting stuck in local suboptimal solutions and is very helpful to maintain the wealth of the population in dealing with large-scale problems. Figure 7 shows the mutation operator used in this paper.

\subsection{Software specification}

All mathematical models are coded in GAMS 24.1.2 and solved by the CPLEX in terms of three separate

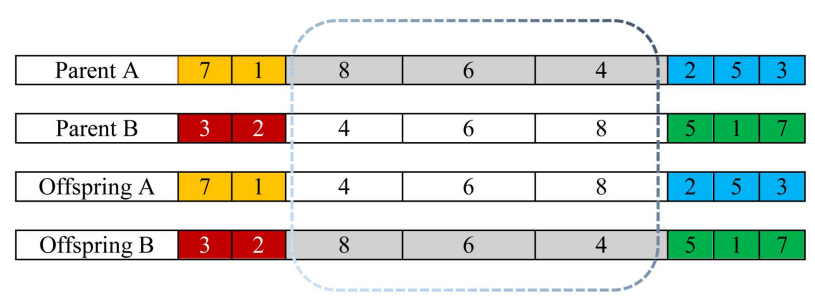

Figure 6. Applied two-point crossover operator.

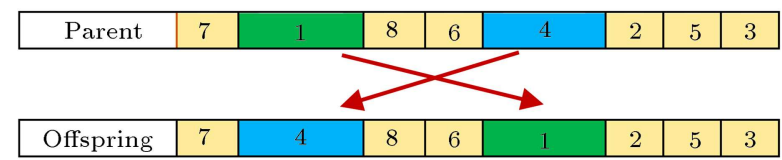

Figure 7. Applied mutation operator. single-objective problems. Also, the generated test instances are implemented in MATLAB 7.11.0 and run on a PC with a $3.4 \mathrm{GHz}$ Intel ${ }^{\circledR}$ Core $^{\mathrm{TM}}$ i7-2600 processor and 4 GB RAM memory.

\section{Experimental design}

Parameter tuning has an important effect on the efficiency of the meta-heuristic algorithms. Among several ways of calibrating the algorithms, one can mention full factorial experiment [43]. This approach is not always effective, especially when the number of factors becomes considerably large. With the intention of reducing the number of required experiments, a Fractional Factorial Experiment (FFE) was developed [44]. FFE allows only a segment of the total possible combinations to approximate the main effect of the factors and some of their interactions. Taguchi (1986) developed a family of FFE matrices which finally diminished the number of experiments, but still provided satisfactory evidence [45]. Orthogonal arrays are employed in Taguchi method to study a large number of decision variables with a small number of tests.

Taguchi separates the factors into two main categories: controllable factors $(S)$ and noise factors $(N)$. Noise factors, as it is implied in the name, are those that one cannot directly control. Since it is impossible to completely eliminate the noise factors, the Taguchi method tries to minimize the effect of noise and, simultaneously, determine the optimal level of the important controllable factors based on the concept of robustness [46]. Besides determining the optimal levels, Taguchi established the relative importance of individual factors in terms of their main effects on the objective function [47].

Taguchi created a conversion of the repetition data to another value, which was the measure of variation. This conversion is called signal-to-noise $(S / N)$ ratio, which describes why this type of parameter design is named a robust design [48]. The term 'signal' shows the desirable value (response variable) and 'noise' indicates the undesirable value (standard deviation). Accordingly, the $\mathrm{S} / \mathrm{N}$ ratio determines the amount of existing variation within the response variable (Eq. (25)). Here, maximization of the signalto-noise ratio is addressed.

$$
S / N \text { ratio }=-10 \log \left(\frac{M I D}{s p}\right)^{2},
$$

where $s p$ signifies spacing, which measures the standard deviation of the distances among solutions of the Pareto front [49] and MID signifies "mean ideal distance" and measures the convergence rate of Pareto fronts to a certain point [50]. These two measures are 
Table 2. Factor levels for sample instances.

\begin{tabular}{cccc}
\hline Factor & Symbol & Levels & Type of problems \\
\hline$p_{c}$ & A & 3 & $\mathrm{~A}(1)=0.6, \mathrm{~A}(2)=0.75, \mathrm{~A}(3)=0.9$ \\
$p_{m}$ & $\mathrm{~B}$ & 3 & $\mathrm{~B}(1)=0.05, \mathrm{~B}(2)=0.1, \mathrm{~B}(3)=0.2$ \\
npop & $\mathrm{C}$ & 3 & $\mathrm{C}(1)=50, \mathrm{C}(2)=100, \mathrm{C}(3)=200$ \\
\hline
\end{tabular}

common measurement factors considered in calculating $S / N$ ratio, since in Pareto-based multi-objective algorithms, two main goals comprising "good convergence" and "diversity" are sought [51].

\subsection{Data generation and setting}

An experiment is conducted to test the performance of the used algorithms. Three factors are considered as control factors in this research, namely, crossover rate $\left(p_{c}\right)$, mutation rate $\left(p_{m}\right)$, and population size $(n p o p)$, each of which has three levels. Table 2 shows the factor levels for the applied sample problems.

Since there are three three-level factors in this research, the total number of trials required for each group would be a full combination of $27\left(3^{3}\right)$ trials, rather than 9 trials, by the orthogonal array $L_{9}\left(3^{3}\right)$.

\subsection{NSGAII parameters tuning based on Taguchi method}

As already mentioned, parameter tuning can significantly increase the solutions quality of the metaheuristic algorithms. An effort has been put to tuning the parameters for the aforementioned factors, i.e., crossover rate $\left(p_{c}\right)$, mutation rate $\left(p_{m}\right)$, and population size (npop). Table 3 shows the Taguchi orthogonal
Table 3. Taguchi orthogonal array design.

\begin{tabular}{cccc}
\hline No & $p_{c}$ & $p_{m}$ & nрop \\
\hline 1 & 1 & 1 & 1 \\
2 & 1 & 2 & 2 \\
3 & 1 & 3 & 3 \\
4 & 2 & 1 & 2 \\
5 & 2 & 2 & 3 \\
6 & 2 & 3 & 1 \\
7 & 3 & 1 & 3 \\
8 & 3 & 2 & 1 \\
9 & 3 & 3 & 2 \\
\hline
\end{tabular}

array design applied in this research, which has been extracted from Minitab software.

After obtaining the results of the Taguchi experiment for all the trials, all objective functions are individually transformed into $S / N$ ratios. Figure 8 illustrates the effect plot for $S / N$ ratio obtained at each level for the sample problems. In this research, each test instance is run 3 times and the average solution values are obtained and used for performance evaluations. As indicated in Figure 8, the optimal level of factor $\mathrm{A}$ is $\mathrm{A}(1)$, while the optimum level of factor $\mathrm{B}$ is $\mathrm{B}(2)$. Also, $\mathrm{C}(3)$ could be selected

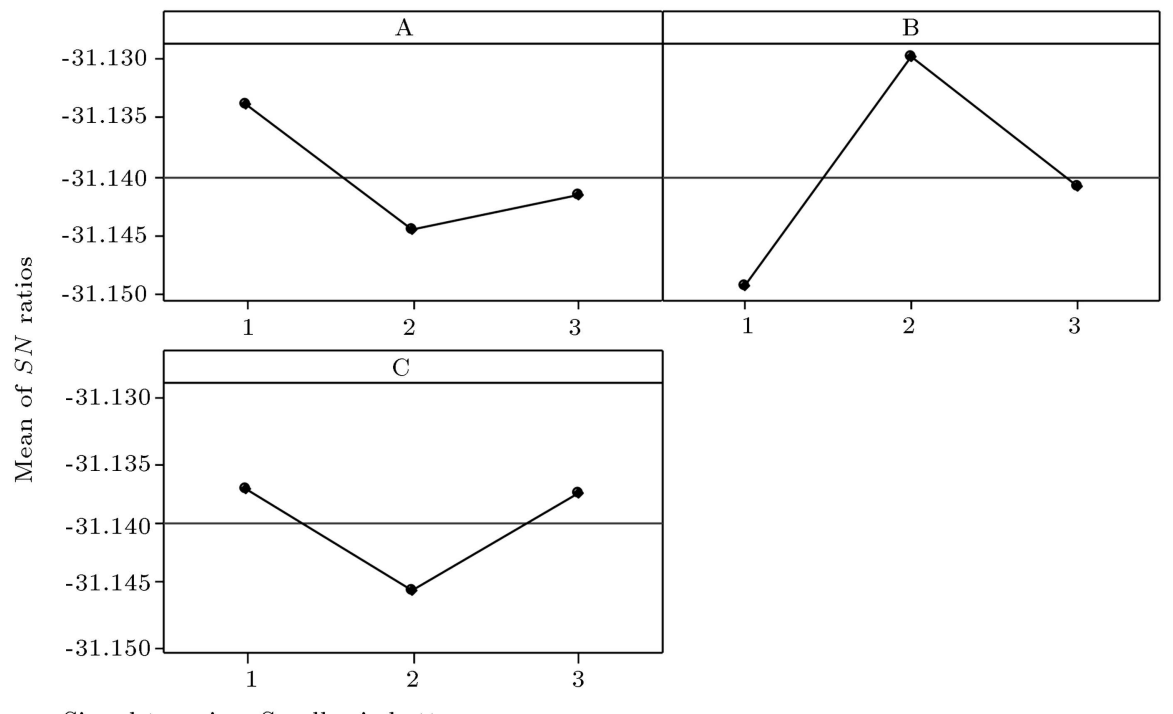

Signal-to-noise: Smaller is better

Figure 8. Main effect plot for $S / N$ ratios. 
as the optimum level of factor $\mathrm{C}$; however, $\mathrm{C}(1)$ has comparable performance.

\section{Computational results}

The computation steps of the decision-making process in this research consist in the following three parts:

Step 1. Transforming the multi-objective mathematical model into several single-objective models and solving them separately to obtain the best/ideal solutions for each objective. The obtained values are then used to tune the boundaries of criteria, namely, "superior," "parity," and "advantage." Strategic decisions are applied to lower levels as scenarios to tune their parameters.

They are run only once and their results are used in all scenarios;

Step 2. Solving the multi-objective model using NSGAII so as to achieve the feasible solutions to the entire problem.

They are run only once and their results are used in all scenarios;

Step 3. Applying TOPSIS method in order to determine the best solutions/individuals based on the decision maker's idea with respect to minimum distance from the ideal solutions.

They should be run independently for each scenario to specify the results of any specific scenario. The computational results are obtained from the three sections.

The decision-making structure, how decisions are aligned based on a top-down approach, and numerical results are presented in Tables 4 and 5 . Table 4 shows the consequences of running the first step. Nonnumerical rows show the multilevel integrated model structure. Columns A to $\mathrm{L}$ represent the concept of each number in rows. Each of the numbered rows shows a complete decision-making scenario including the strategy setting and the operational plan that are aligned with each other.

Columns A to $\mathrm{C}$ represent a strategic scenario. In the highest level of SCPM, human-intelligence determines the objective priorities based on SCOR metrics. These priorities define the strategies in the next period. All programs in low levels are implemented based on these priorities.

In columns $\mathrm{D}$ to $\mathrm{F}$, the optimum objective functions for the strategic scenario are presented. Columns $G$ to $L$ show the values of objective functions in a discrete form for the supplier and manufacturer. Note that the manufacturer cannot produce without components and, as a result, the reliability of the supplier is constant for all scenarios and, therefore, is not considered in calculations. Each record in operational level suggests an operational production and supply plan, which is not described here for the sake of brevity.

In Table 4, rows 1 to 3 present the scenarios in which each of the objectives has been optimized in a single-objective form. The second row is explained for more clarity. In the designed scenario, SC's strategy is to maximize the agility; therefore, W2 becomes 1 and other weights become 0. By setting these weights for the multi-objective model and solving the model, the maximum value of 176 is obtained for agility. In this scenario, cost is 479 and reliability is 17 . Agility of the third scenario deviates by 56 units from the second scenario's agility, which optimizes reliability. Reliability in the third scenario with the best possible program for this metric is 30 .

Once the best possible solution is given for each objective, they are used to determine the benchmark levels. As shown in Table 1, levels of metrics can be classified into three benchmark levels. There are four methods that can be used to set performance targets: theoretical targets, historical based, external benchmarks, and internal benchmarks (internal "best in class" practice) $[52,53]$. This example only tries to show the operation mechanism of the proposed framework. For determining parity and advantage values, the objective values of 1 to 3 are used for the scenario. We assume that this set provides good internal range for determining superior, advantage, and parity values (the end of Table 4 ).

The complete calculations of Step 2 are not presented for the sake of brevity. However, the complete results of Step 3 are presented in Table 5 .

Each record of Table 5 has two main parts. Columns A, B, and C determine simultaneous strategy so as to get the specified level of three main objectives. Columns D to L signify the best operational decision to reach the determined strategy. In this regard, the operational decision is output of Step 3.

This solution is determined by comparing all obtained Pareto solutions from Step 2 considering given strategic priorities (according to Figure 3). However, depending on strategists' priorities for the objectives, different scenarios will be generated. As an example, in the presented scenario in row 9 , the most important objective ( $S=$ Superior) is minimizing cost, the second most important goal is maximizing agility ( $A$ $=$ Advantage), and maximizing reliability is the least important one ( $P=$ Parity). According to this strategy and by implementing the third computational step, the best solution among Pareto solutions is determined. In this solution, the total cost is 364 , agility is equal to 138 , and reliability is 17 ; the values of 8 sets of model variables are specified as well. In Table 6 , only the values of $X_{n i j t}$ of scenario \#9 are presented for the sake of brevity and the rest of values are zero. 
Table 4. Defined target values for strategic objectives.

\begin{tabular}{|c|c|c|c|c|c|c|c|c|c|c|c|c|}
\hline & \multicolumn{12}{|c|}{ Supply chain decision alignment } \\
\hline & $\mathrm{A}$ & $\mathrm{B}$ & & $\mathrm{C}$ & $\mathrm{D}$ & $\mathrm{E}$ & $\mathrm{F}$ & $\mathrm{G}$ & $\mathrm{H}$ & I & $\mathrm{J}$ & \begin{tabular}{l|l}
$\mathrm{K}$ & $\mathrm{L}$ \\
\end{tabular} \\
\hline & \multicolumn{4}{|c|}{ Human decision level } & \multicolumn{2}{|c|}{ Intermediate decision level } & \multicolumn{6}{|c|}{ Machine decision level } \\
\hline \multirow{3}{*}{ 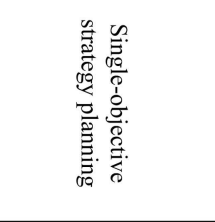 } & 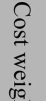 & 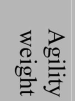 & 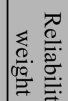 & \multicolumn{3}{|c|}{$\begin{array}{c}\text { Ideal point } \\
\text { (Best for each objective) }\end{array}$} & \multicolumn{6}{|c|}{$\begin{array}{l}\text { Best for each echelon S (Supplier), M } \\
\text { (Manufacturer) }\end{array}$} \\
\hline & \multirow{2}{*}{\multicolumn{3}{|c|}{$\begin{array}{l}\text { Goals setting } \\
\text { (Strategy level) }\end{array}$}} & \multirow{2}{*}{$\begin{array}{l}\text { Cost } \\
\text { (Min) }\end{array}$} & \multirow{2}{*}{$\begin{array}{l}\text { Agility } \\
\text { (Max) }\end{array}$} & \multirow{2}{*}{$\begin{array}{l}\text { Reliability } \\
\text { (Max) }\end{array}$} & \multicolumn{2}{|c|}{ Min (sum) } & \multicolumn{2}{|c|}{ MaxMin } & \multicolumn{2}{|c|}{ Max } \\
\hline & & & & & & & $\mathrm{S}$ & $\mathrm{M}$ & $\mathrm{S}$ & $\mathrm{M}$ & $S$ & $\mathrm{M}$ \\
\hline Minimize cost & 1 & 0 & 0 & 349 & 120 & 25 & 230 & 119 & 45 & 75 & & 25 \\
\hline Maximize agility & 0 & 1 & 0 & 479 & 176 & 17 & 161 & 318 & 91 & 85 & & 17 \\
\hline Maximize reliability & 0 & 0 & 1 & 409 & 120 & 30 & 237 & 172 & 45 & 75 & & 30 \\
\hline
\end{tabular}

All mathematical models are coded in GAMS 24.1.2 and solved through the CPLEX in terms of three separate single-objective problems.

\begin{tabular}{|c|c|c|c|}
\hline \multicolumn{4}{|c|}{ Target setting (Strategy level) } \\
\hline $\mathrm{S}=$ Superior & 349 & 176 & 30 \\
\hline $\mathrm{A}=$ Advantage & $\leq 380$ & $\geq 150$ & $\geq 26$ \\
\hline $\mathrm{P}=$ Parity & $\leq 4100$ & $\geq 120$ & $\geq 20$ \\
\hline
\end{tabular}

Table 5. Strategic scenarios for performance, values of objectives, and operational programs.

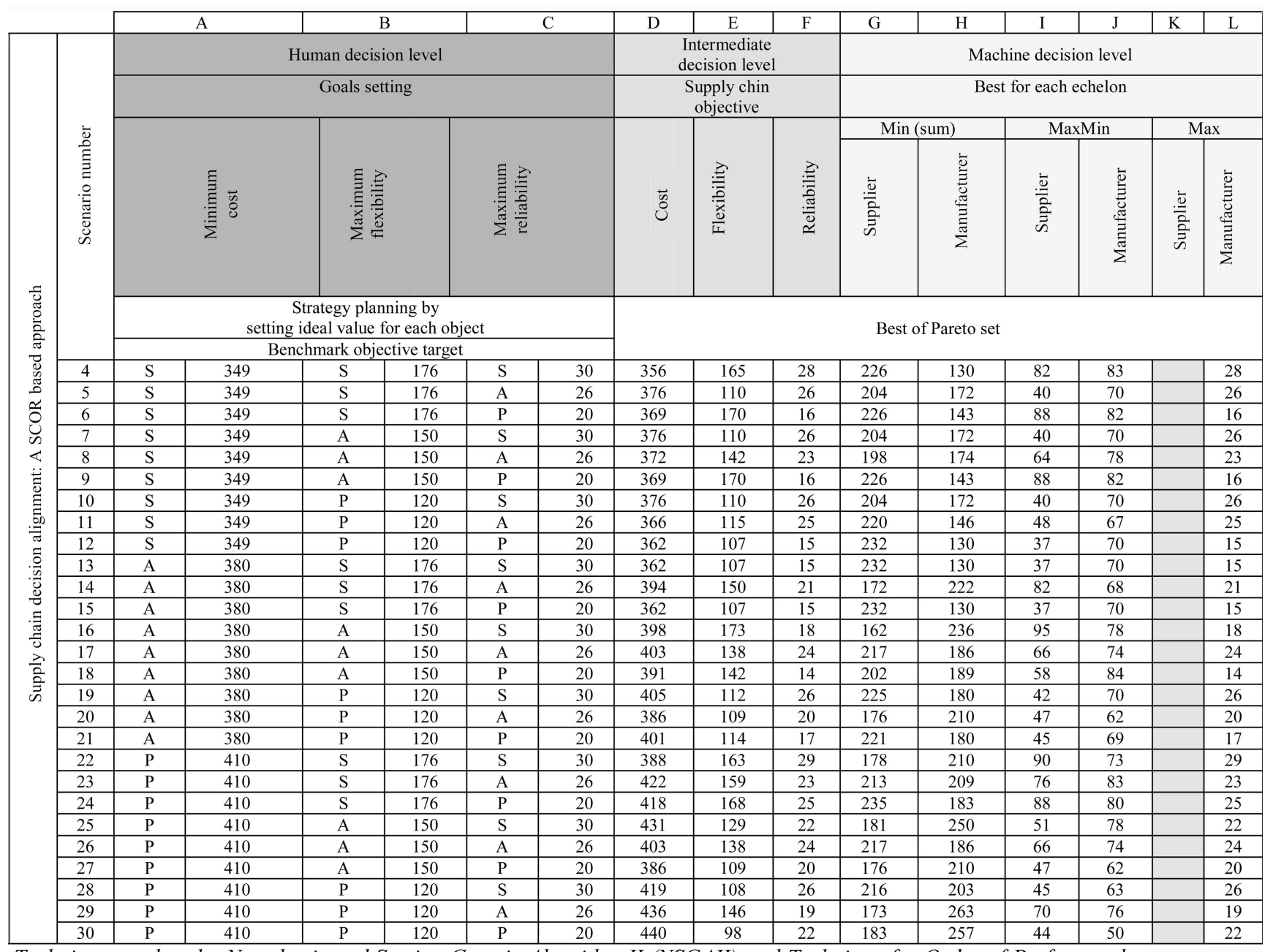

Techniques and tools: Non-dominated Sorting Genetic Algorithm II (NSGAII) and Technique for Order of Preference by Similarity to Ideal Solution (TOPSIS). 
Table 6. $X_{\text {nijt }}$ (the amount of supplied material $n$ by supplier $i$ to plant $j$ in period $t$ ).

\begin{tabular}{|c|c|c|c|c|c|c|}
\hline n1.i1.j2.t2 & n1.i1.j2.t3 & n1.i1.j2.t4 & n1.i2.j1.t2 & n1.i2.j1.t3 & n1.i3.j1.t4 & n2.i1.j1.t3 \\
\hline 8 & 1 & 3 & 6 & 9 & 7 & 6 \\
\hline n2.i1.j2.t4 & n2.i2.j2.t2 & n2.i3.j1.t2 & n2.i3.j1.t4 & n2.i3.j2.t3 & n3.i1.j1.t2 & n3.i1.j1.t4 \\
\hline 3 & 6 & 4 & 4 & 2 & 3 & 8 \\
\hline n3.i1.j2.t3 & n3.i2.j1.t3 & n3.i2.j2.t2 & n3.i3.j1.t2 & n3.i3.j1.t3 & n3.i3.j2.t2 & n3.i3.j2.t4 \\
\hline 4 & 3 & 8 & 3 & 9 & 2 & 6 \\
\hline
\end{tabular}

\subsection{Sensitivity analysis}

As already mentioned, the first and second computational steps in all scenarios are implemented only once. The third step should be run again by any change in strategies. Model sensitivity with respect to these changes is investigated in this section. Such a sensitivity investigation clearly illustrates the relation between operational and strategic levels.

In Figure 9, the effects of bound variations of 'superior,' 'parity,' and 'advantage' in strategic level are shown. Changing the selected numbers within acceptable range of strategic objectives in the third last record of Table 4, the behavior of the model in choosing the optimum point changes. In this condition, the changes have no impact on the generation of Pareto solutions. These changes affect weights of the ideal point in TOPSIS model and lead to creation of different final alternatives among a fixed Pareto set of solutions as the final selected point by the comprehensive model. In Figure 9, the acceptable levels of objectives are divided into 10 parts and, consequently, 10 different points are specified so as to determine the strategy level (Table 7).

Applying these 10 points in weighting ideal TOP-

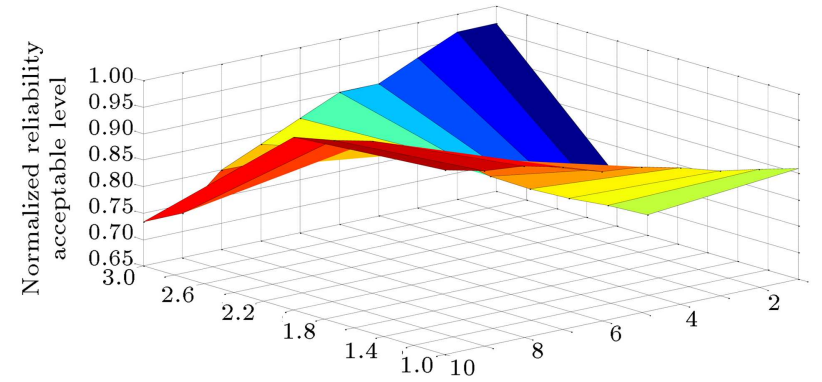

Normalized cost acceptable level Normalized agility acceptable level

Figure 9. Pareto optimal non-dominated solutions obtained via NSGAII.
SIS, we illustrate how one can select different points in a Pareto set with 10 members/solutions through changing acceptable levels. The results are shown in a 3-dimensional space in Figure 9.

\section{Conclusions and future studies}

This study presented a comprehensive framework for SC performance improvement using a dynamic alignment of strategic and low-level decisions. Generally, to the best of the authors' knowledge, there is no outstanding research in the literature in which the mentioned criteria have simultaneously been investigated.

Two echelons consisting of suppliers and manufacturers were considered in the proposed SC. The presented operational model carefully considered important SC features such as several suppliers, several plants, several materials, and several products during multiple periods. The operational model aimed at minimizing the supply cost and production cost as well as maximizing supply agility, production agility, and $\mathrm{SC}$ reliability.

The results of computational experiments demonstrated the operation of the proposed solution method. Then, a sensitivity analysis was conducted on the parameters, and scenarios of the proposed approach and the results were discussed. The main contributions of this framework could be classified as follows:

1. Improved performance indicators by aligning all SC decisions;

2. Using SCOR model for presenting an integrated, simultaneous, and connected framework for performance evaluation and improvement at the whole SCM levels;

3. Providing a human-intelligence based decisionmaking process for strategic plan setting;

Table 7. The acceptable levels.

\begin{tabular}{|l|c|c|c|c|c|c|c|c|c|c|}
\cline { 2 - 11 } \multicolumn{1}{c|}{} & P1 & P2 & P3 & P4 & P5 & P6 & P7 & P8 & P9 & P10 \\
\hline Cost acceptable level & 352 & 358 & 363 & 372 & 379 & 382 & 392 & 399 & 402 & 409 \\
\hline Normalized cost acceptable level & 0.858 & 0.873 & 0.885 & 0.907 & 0.924 & 0.931 & 0.956 & 0.973 & 0.980 & 0.997 \\
\hline Agility acceptable level & 121 & 127 & 132 & 138 & 145 & 154 & 158 & 165 & 168 & 172 \\
\hline Normalized agility acceptable level & 0.687 & 0.721 & 0.75 & 0.784 & 0.823 & 0.875 & 0.897 & 0.937 & 0.954 & 0.977 \\
\hline Reliability acceptable level & 22 & 22 & 24 & 25 & 26 & 27 & 27 & 28 & 29 & 29 \\
\hline Normalized reliability acceptable level & 0.733 & 0.733 & 0.8 & 0.833 & 0.866 & 0.9 & 0.9 & 0.933 & 0.966 & 0.966 \\
\hline
\end{tabular}


4. Providing a machine-intelligence based decisionmaking process for quantitative modelling of the low levels.

Moreover, the main contributions of the operational model can be listed as follows:

1. Considering cost, agility, and reliability as objective functions in a two-echelon SC, simultaneously, according to SCOR model;

2. Analyzing the behavior of the proposed approach using a sensitivity analysis considering several scenarios.

Due to using different methodologies and scientific concepts, the proposed Supply Chain Performance Management (SCPM) framework provides a reliable structure and has many practical applications in different areas. However, based on the capabilities of this framework, the following future developments are proposed:

1. Expansion of the model under stochastic programming or fuzzy set theory by taking into account the parameters of demand, cost, and processing times;

2. Adding other SC features such as "distribution" to the proposed model.

\section{References}

1. Masoumi, M.K., Salwa Hanim, A., Ezutah, O., et al. "An integrated framework-for designing a strategic green supply chain with an application to the automotive industry", International Journal of Industrial Engineering, 22(1), pp. 46-61 (2015).

2. Bai, C. and Sarkis, J. "Supply-chain performancemeasurement system management using neighbourhood rough sets", International Journal of Production Research, 50(9), pp. 2484-2500 (2012).

3. Sellitto, M.A., Pereira, G.M., Borchardt., M., et al. "A SCOR-based model for supply chain performance measurement: application in the footwear industry", International Journal of Production Research, 53(16), pp. 4917-4926 (2015).

4. Alomar, M. and Pasek, Z.J. "Linking supply chain strategy and processes to performance improvement", Procedia CIRP, 17, pp. 628-634 (2014).

5. Badri, H., Ghomi, S.F., and Hejazi, T. "A two-stage stochastic programming model for value-based supply chain network design", Scientia Iranica. Transaction E, Industrial Engineering, 23(1), p. 348 (2016).

6. Skipworth, H., Godsell, J., Wong, C.Y., et al. "Supply chain alignment for improved business performance: an empirical study", Supply Chain Management: An International Journal, 20(5), pp. 511-533 (2015).

7. Estampe, D., Lamouri, S., Paris, J.L., et al., "A framework for analysing supply chain performance evaluation models", International Journal of Production Economics, 142(2), pp. 247-258 (2013).
8. Singh, R.K. and Acharya, P. "Performance evaluation of supply chain management systems: a critical review of literature", International Journal of Procurement Management, 7(2), pp. 201-218 (2014).

9. Stefan Schaltegger, P.R.B., Dr, Bai, C., and Sarkis, J. "Determining and applying sustainable supplier key performance indicators", Supply Chain Management: An International Journal, 19(3), pp. 275-291 (2014).

10. Ntabe, E.N., Lebel, 1., Munson, A.D., et al. "A systematic literature review of the supply chain operations reference (SCOR) model application with special attention to environmental issues", International Journal of Production Economics, 169, pp. 310-332 (2015).

11. Agami, N., Saleh, M., and Rasmy, M. "A hybrid dynamic framework for supply chain performance improvement", Systems Journal, IEEE, 6(3), pp. 469-478 (2012).

12. Kocaoğlu, B., Gülsün, B., and Tanyaş, M. "A SCOR based approach for measuring a benchmarkable supply chain performance", Journal of Intelligent Manufacturing, 24(1), pp. 113-132 (2013).

13. Beamon, B.M. "Measuring supply chain performance", International Journal of Operations \& Production Management, 19(3), pp. 275-292 (1999).

14. Gunasekaran, A., Patel, C., and Tirtiroglu, E. "Performance measures and metrics in a supply chain environment", International Journal of Operations \& Production Management, 21(1/2), pp. 71-87 (2001).

15. Cai, J., Liu, X., Xiao, Z., et al. "Improving supply chain performance management: A systematic approach to analyzing iterative KPI accomplishment", Decision Support Systems, 46(2), pp. 512-521 (2009).

16. Elgazzar, S.H., Tipi, N.S., Hubbard, N.J., et al. "Linking supply chain processes' performance to a company's financial strategic objectives", European Journal of Operational Research, 223(1), pp. 276-289 (2012)

17. Rooeinfar, R., Azimi, P., and Pourvaziri, H. "Multiechelon supply chain network modelling and optimization via simulation and metaheuristic algorithms", Scientia Iranica, 23(1), pp. 330-347 (2016).

18. Agami, N., Saleh, M., and Rasmy, M. "An innovative fuzzy logic based approach for supply chain performance management", Systems Journal, IEEE, 8(2), pp. 336-342 (2014).

19. Blanco, V. "A mathematical programming approach to the computation of the omega invariant of a numerical semigroup", European Journal of Operational Research, 215(3), pp. 539-550 (2011).

20. Liu, S. and Papageorgiou, L.G. "Multiobjective optimisation of production, distribution and capacity planning of global supply chains in the process industry", Omega, 41(2), pp. 369-382 (2013).

21. Hamta, N., Fatemi Ghomi, S.M.T., Jolai, F., et al. "A hybrid PSO algorithm for a multi-objective assembly line balancing problem with flexible operation 
times, sequence-dependent setup times and learning effect", International Journal of Production Economics, 141(1), pp. 99-111 (2013).

22. Kolahan, F. and Kayvanfar, V. "A heuristic algorithm approach for scheduling of multi-criteria unrelated parallel machines", World, Academy of Science, Engineering and Technology, 59, p. 102 (2009).

23. Celik, N., Nageshwaraniyer, S.S., and Son, Y.-J. "Impact of information sharing in hierarchical decisionmaking framework in manufacturing supply chains", Journal of Intelligent Manufacturing, 23(4), pp. 10831101 (2012).

24. Aalaei, A. and Davoudpour, H. "Revised multi-choice goal programming for incorporated dynamic virtual cellular manufacturing into supply chain management: a case study", Engineering Applications of Artificial Intelligence, 47, pp. 3-15 (2016).

25. Tamiz, M., Jones, D., and Romero, C. "Goal programming for decision-making: An overview of the current state-of-the-art", European Journal of Operational Research, 111(3), pp. 569-581 (1998).

26. Slomp, J., Chowdary, B.V., and Suresh, N.C. "Design of virtual manufacturing cells: a mathematical programming approach", Robotics and ComputerIntegrated Manufacturing, 21(3), pp. 273-288 (2005).

27. Mahdavi, I., Aalaei, A., Paydar, M.M., et al. "Multiobjective cell formation and production planning in dynamic virtual cellular manufacturing systems", International Journal of Production Research, 49(21), pp. 6517-6537 (2011).

28. Wong, J.-T. "DSS for 3PL provider selection in global supply chain: combining the multi-objective optimization model with experts' opinions", Journal of Intelligent Manufacturing, 23(3), pp. 599-614 (2012).

29. Xu, J., Jiang, B., Tang, L., et al., A Multi-Objective Coordinated Operation Model for Supply Chain with Uncertain Demand Based on Fuzzy Interval (2013).

30. Cai, Z., Wang, Y., Xiao, R., et al. "A multi-agentdriven closed-loop quality chain model and coordinated optimization", Communications in Information Science and Management Engineering, 3(11), p. 524 (2013).

31. Zhang, W. and Reimann, M. "Towards a multiobjective performance assessment and optimization model of a two-echelon supply chain using SCOR metrics", Central European Journal of Operations Research, 22(4), pp. 591-622 (2014).

32. Ramaa, A., Rangaswamy, T., and Subramanya, K. "A review of literature on performance measurement of supply chain network", in Emerging Trends in Engineering and Technology (ICETET), 2nd International Conference on, IEEE (2009).

33. Damodaran, A., Applied Corporate Finance: A User's Manual, John Wiley \& Sons (2008).
34. Teran, H., Hernandez, J., Vizán, A., et al. "Performance measurement integrated information framework in e-Manufacturing", Enterprise Information Systems, 8(6), pp. 607-629 (2014).

35. Hearnshaw, E.J. and Wilson, M.M. "A complex network approach to supply chain network theory", International Journal of Operations \& Production Management, 33(4), pp. 442-469 (2013).

36. Trkman, P., Budler, M., and Groznik, A. "A business model approach to supply chain management", Supply Chain Management: An International Journal, 20(6), pp. 587-602 (2015).

37. Arzu Akyuz, G. and Erman Erkan, T. "Supply chain performance measurement: a literature review", International Journal of Production Research, 48(17), pp. 5137-5155 (2010).

38. Wang, W.Y., Chan, H.K., and Pauleen, D.J. "Aligning business process reengineering in implementing global supply chain systems by the SCOR model", International Journal of Production Research, 48(19), pp. 5647-5669 (2010).

39. Li, L., Su, Q., and Chen, X. "Ensuring supply chain quality performance through applying the SCOR model", International Journal of Production Research, 49(1), pp. 33-57 (2011).

40. Francis, J., Supply Chain Management \& Business Financial Performance (2009).

41. Sabri, E.H. and Beamon, B.M. "A multi-objective approach to simultaneous strategic and operational planning in supply chain design", Omega, 28(5), pp. 581-598 (2000).

42. Deb, K., Pratap, A., Agarwal, S., et al. "A fast and elitist multi objective genetic algorithm: NSGA-II" IEEE transactions on evolutionary computation, 6(2), pp. 182-197 (2002).

43. Montgomery, D.C., Design and Analysis of Experiments, 5th Ed. New York: Wiley (2000).

44. Cochran, W.G. and Cox, G.M., Experimental Designs, 2nd Ed. New York: Wiley (1992).

45. Taguchi, G., Introduction to Quality Engineering, White Plains. Asian Productivity, pp. 21-22 (1986).

46. Tsai, J.-T., Ho, W., Liu, T., et al. "Improved immune algorithm for global numerical optimization and jobshop scheduling problems", Applied Mathematics and Computation, 194(2), pp. 406-424 (2007).

47. Kayvanfar, V. and Zandieh, M. "The economic lot scheduling problem with deteriorating items and shortage: an imperialist competitive algorithm", The International Journal of Advanced Manufacturing Technology, 62(5-8), pp. 759-773 (2012).

48. Al-Aomar, R. "Incorporating robustness into genetic algorithm search of stochastic simulation outputs", Simulation Modelling Practice and Theory, 14(3), pp. 201-223 (2006). 
49. Scott, J. "Fault tolerant design using single and multicriteria genetic algorithms", Master's Thesis, Department of Aeronautics and Astronautics, Massachusetts Institute of Technology (1995).

50. Zitzler, E. and Thiele, L. "Multiobjective optimization using evolutionary algorithms - a comparative case study", in International Conference on Parallel Problem Solving from Nature, Springer (1998).

51. Kayvanfar, V., Zandieh, M., and Mahdavi, I. "Economic lot scheduling problem with allowable shortage: a multi-objective approach", in Industrial Engineering and Engineering Management (IE \&EM), 2011 IEEE 18 Th International Conference on, IEEE (2011).

52. Lapide, L. "What about measuring supply chain performance", Achieving Supply Chain Excellence Through Technology, 2, pp. 287-297 (2000).

53. Peng Wong, W. and Yew Wong, K. "A review on benchmarking of supply chain performance measures", Benchmarking: An International Journal, 15(1), pp. 25-51 (2008).

\section{Biographies}

Mahdi Rezaei is a PhD degree candidate in the Department of Industrial Engineering at Amirkabir University of Technology, Tehran, Iran. His research interests are supply chain performance management, multiple criteria decision-making, and IoT.

Mohsen Akbarpour Shirazi received his PhD degree in Industrial Engineering from Amirkabir University of Technology, Tehran, Iran, where he is now Assistant Professor. His areas of research include supply chain planning, transportation, and modeling. $\mathrm{He}$ is author and co-author of many technical papers in these fields.

Behrooz Karimi received his $\mathrm{PhD}$ degree in Industrial Engineering, in 2002, from Amirkabir University of Technology, Tehran, Iran, where he is now Professor. His areas of research include supply chain planning, scheduling, and simulation. 